\title{
THE BESPOKE APPROACH TO DEVELOPING AND DELIVERING ONLINE STAFF DEVELOPMENT
}

\author{
Lindsey Martin \\ Academic Liaison Co-ordinator, Learning Services \\ Edge Hill College of Higher Education \\ Ormskirk, Lancashire, L39 4QP. UK. \\ martinl@edgehill.ac.uk
}

\begin{abstract}
:
The library at Edge Hill has been closely involved with the institution's virtual learning environment (VLE), WebCT since its introduction in 1999. Early library activity with WebCT focused on collaborating with learning technologists and academics to embed electronic resources, and support students through the Help Desks. Ongoing involvement has resulted in the library, now part of a converged Learning Services, creating a suite of online staff development modules. This paper will describe how an e-learning ethos has been engendered within the service. It will also describe the suite of online courses available to Learning Services staff, explaining why bespoke online courses were created. It will describe the underpinning pedagogy and the process of developing and delivering these courses in a way that ensures that the technology adds value to the learning. The paper will use the most recently developed online module, Customer Care, as a case study. This module provides a context-rich, theoretical and practical grounding in customer care for staff in a converged service. The case study will describe the beta testing of the module and the learner feedback. It will consider the future challenges for e-learning support and development within the department.
\end{abstract}

\section{Introduction}

The Library at Edge Hill College has been closely involved with the institution's virtual learning environment (VLE), WebCT since its introduction in 1999. Early library activity with WebCT focused on collaborating with learning technologists and academics to embed electronic resources, and support students through the Help Desks. Ongoing involvement has resulted in the library, now part of a converged Learning Services, creating a suite of online staff development modules. A strategic approach was established to harness the potential of WebCT as a tool for developing, delivering and supporting teaching and learning within the service. This has from the earliest days seen WebCT used as the medium for delivery of staff training and development because according to Salmon, ${ }^{1}$ those designing, delivering and supporting online courses need to experience first hand the 'pitfalls and potential' of the online medium in order to create an effective learning experience.

This paper will describe the suite of online courses available to Learning Services staff. It will explain why bespoke online courses were created rather than buying 'off the shelf' and it will describe the underpinning pedagogy and the process of developing and delivering these courses in a way that ensures that the technology adds value to the learning. The paper will use the most recently developed online module, Customer Care, as a case study. This module has won the Accessing Lancashire Library and Information Services (ALLIS) Staff Development Award for 2004. 


\section{E-learning and UK higher education}

Technology has transformed the information landscape and the way that learning is facilitated and experienced. Higher Education institutions today cannot afford to be without their Virtual Learning Environments, online databases, electronic journals and eBooks. For the most part, these are no longer considered to be 'new' technology. Perceived pedagogical advantage, the rapid growth of distributed forms of learning and more cynically, the hope of gaining a competitive advantage in the Higher Education marketplace are among the many drivers that have brought about this change.

There is no doubt that Colleges and Universities are rich in technology and this has resulted in high expectations that academic staff and students will engage as early as possible in their academic careers with that technology, using it as a tool for both communicating and learning. In return, academics and students have high expectations of what the technology can do for them. There is a clear 'skills gap' in the space between the ability of academics and students to use technology and their expectations and furthermore, there is, according to Gilbert, ${ }^{2}$ a widening gap between these expectations and the resources and services available to support them, to the extent that he describes it as a 'support service crisis'.

Despite the growing numbers of students who own computers and their general familiarity with information technology, the available research suggests that the majority have not yet developed the necessary e-literacy skills that will enable them to learn in this information age. ${ }^{3,4}$ Access to technology is not the same as understanding, which requires cognitive skills that extend beyond information skills to include communication and an adaptation to learning online. Their development is dependent upon staff at all levels in library and information services being able to offer support, services, training and resources, all at point of need, regardless of time and place.

While there is little consistency in how academic library and information services have adapted to and developed e-learning initiatives, many staff across the profession are becoming increasingly involved at all levels, for example, in the discovery and embedding of electronic resources, design of materials, face to face support via help desks, e-support and etutoring. ${ }^{5}$ As traditional library and information roles are changing, information professionals are undertaking work that bears little relation to their professional training. The wide-spread acquisition of these new skills and knowledge must therefore be consciously planned for staff at all levels and at every stage of their working life, ${ }^{6}$ along with the promotion of an elearning ethos that accepts 'cultural change, professional identity and boundary crossing'. The remainder of this paper describes the strategies adopted by Edge Hill's Learning Services to develop an e-learning ethos and skills in a wide range of staff and focuses upon the newly developed online Customer Care module as a case study.

\section{The Edge Hill context}

Edge Hill College of Higher Education is a higher education institution in the northwest of England, with over 9,000 students on a range of degree and diploma courses and a further 6,000 on continuing professional development courses, the majority of which are in education and health-related areas. Edge Hill has strong centralised academic support structures, enhanced by the formation of the Learning Services department in 2003. This large department now offers a converged service consisting of learning resource centres, learning support, ICT user support for teaching and learning, media services, e-learning development, study skills and dyslexia support. The administration, development and support of WebCT are, therefore, managed within Learning Services with the staff working closely with academic colleagues. 
The portfolio of teaching and learning programmes at Edge Hill has developed rapidly over recent years. Investment in the development of online teaching and learning has occurred and resulted in delivery both on and off site. WebCT was initially used to deliver a single course, the Postgraduate Certificate in Teaching and Learning in Clinical Practice, which was delivered fully online. Since then, the institution has adopted an incremental rather than a 'big bang' approach to the adoption of WebCT, relying on those 'early adopters' and champions of e-learning to spread the word and showcase what can be achieved. Nevertheless, the rate of expansion of WebCT courses has been considerable and has largely been used to support a blended learning approach. Currently, a total of 400 courses and modules are being delivered across the curriculum, with approximately 8,500 registered users.

\section{E-learning and staff development}

The development of WebCT within the institution has coincided with the worldwide expansion of electronic book and journal publishing. The potential for integrating electronic resources within WebCT has had a huge impact on staff in learning support roles in their identification and purchase of appropriate e-resources and in provision of support and training for students. At an early stage, the service recognised the importance of WebCT and eresources and their likely impact on staff roles across the department. While staff in learning support and learning technology were heavily involved in these developments and were moving towards a multi-professional team model of working, it was clear that the impact would extend to staff providing front-line support on help desks and through off-campus support services.

Initial staff development and training of Learning Services staff was ad hoc and attendance was voluntary, attracting only the early adopters of the new e-learning technology. Training sessions delivered ranged from general awareness raising, Help Desk troubleshooting and password changing to writing and designing materials. It soon became apparent, however, that while staff found the sessions enjoyable and they were well attended, they did not address the issue of all Learning Services staff having awareness of this new medium. Nor did they provide an experience of online learning or WebCT. In order to do this, it was recognised that it would be necessary to embed the use of WebCT into the everyday working practices of all Learning Services staff and to harness WebCT as a vehicle for delivering staff development relating to online learning. This solution was adopted because according to Salmon, "for staff development to be successful, training needs to be rooted in the peculiarities and requirements of the online environment itself" and "if your staff cannot easily navigate, interact, find what they need and fully participate, feel friendly and enthused by your VLE ... why would they expect the students to feel differently?"7

Supporting Learning Services staff with their e-learning role would, therefore, start from the first day of their appointment, irrespective of their job role. A staff development life cycle approach has been developed within Learning Services and provides e-learning opportunities at appropriate stages of the cycle. All staff are expected to reach a baseline understanding of e-learning while developing skills in using WebCT. Two e-mechanisms have been developed within Learning Services that enable this baseline understanding and they are supplemented by practical applications of WebCT; for example, receiving staff training with the Customer Care module and the management of functional tasks such as hosting the Help Desk Intranet and various booking systems.

\section{ProVIDE - a baseline understanding of e-learning}

A resource was created that ensured all staff would use WebCT within their everyday role. It is called ProVIDE (Providing a Virtual Induction and Development Environment) and 
it achieved the Society of Colleges, National and University Libraries (SCONUL) Staff Development Award for innovative practice, 2001. ProVIDE is an information base for all Learning Services staff regardless of their role or position within the department. It offers flexible and equal access to information, support, guidance and training opportunities. It is also a key tool for staff induction, being embedded within the departmental staff development programme.

ProVIDE enables all staff to experience WebCT at a very basic level through developing navigation and information retrieval skills. It contains the following sections (Fig 1):

\section{Figure 1 Design and layout of the main areas of ProVIDE}

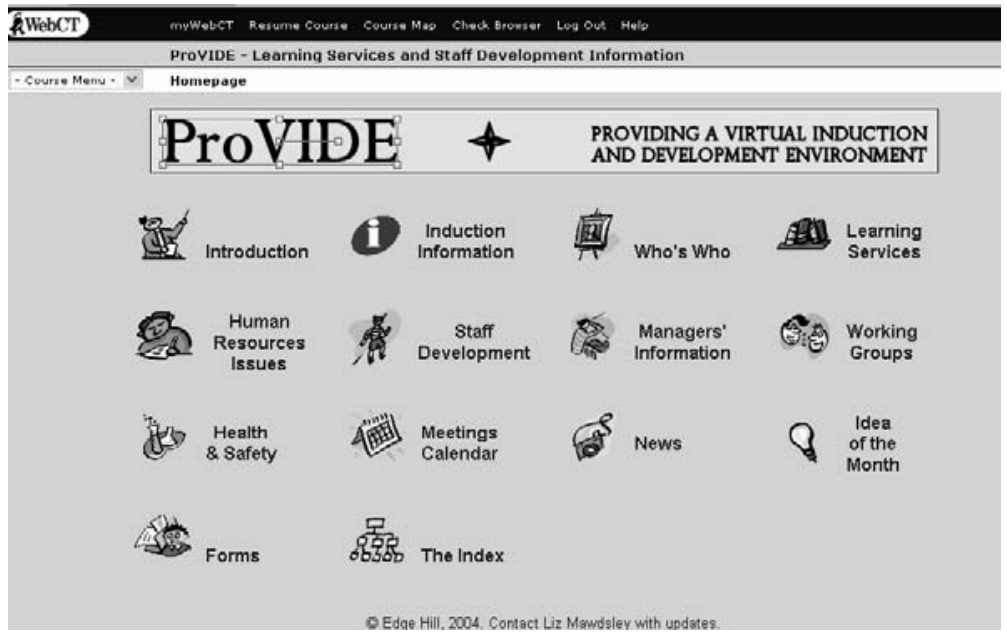

Introduction, provides the context and explains how to use the WebCT tools and navigation.

Induction Information, contains information about Learning Services and the wider institution's staff induction programmes. New staff can view their personal induction timetables and tasks that they are expected to complete in order to demonstrate their use of the information base.

Who's Who, is the profiles tool within WebCT where staff create a personal home page that includes a photograph, information about their job role, working patterns, location and personal interests. We consider this to be an important feature of ProVIDE, giving it a personal and social face.

Learning Services, provides an overview of the service and staffing structures.

Human Resources Issues, contains information about salary matters, annual leave and sickness monitoring.

Staff Development, contains the staff development and mentoring policies together with information about training opportunities within Learning Services, the wider institution and externally.

Managers Information, offers guidance and information for new managers. 
Working Groups, provides details of the formal meetings structure and membership of groups.

Health and Safety, contains the policy, contact information and emergency evacuation procedures.

Meetings Calendar, offers a comprehensive point of access to meeting dates and venues.

News, links to items of current news within the department.

Idea of the Month, offers information and feedback about the 'Idea of the Month' initiative.

Form, are provided electronically and include staff development application forms, annual leave forms, claim forms for additional hours worked.

The Index, is a search tool.

The aim is to organise information consistently within the sections. Each section contains a contents page and an introduction. Content has been organised within the pages to assist users with the rapid scanning of text. This includes use of headings, emboldened text and bulleted lists. A template was devised within DreamWeaver to ensure there was a consistent look to all pages within the resource. After a period of testing and evaluation, ProVIDE was introduced to all staff within the department through face-to-face staff training sessions in IT classrooms where they had an opportunity for a 'hands on' introduction to the resource. These sessions proved to be a lively and positive experience for the project team and the staff - as evidenced by their formal and informal feedback. We have evaluated participants' usage and the statistics show that the resource continues to be used regularly by staff beyond their induction period.

\section{Supporting Online Learning - a four-week module}

A short introductory module was developed to meet the needs of front-line staff. The primary aim was to introduce staff to the e-learning experience while they also learn about the pedagogy and technology. The module runs over a period of four weeks, starting with a faceto-face session. It requires a commitment of approximately 2-4 hours per week and the participants produce a portfolio that consists of their responses to the tasks contained within the module which demonstrate their engagement with the content and each other. The module contains four units (Fig 2):

Figure 2 The four units within Supporting Online Learning.

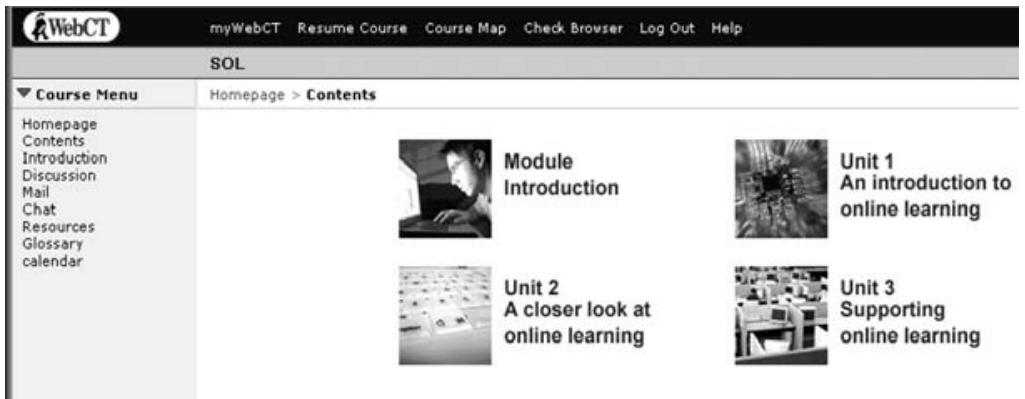


Module Introduction: an opportunity to acclimatise to the online environment with a general overview of the module, its aims and learning outcomes, structure, learner guidelines and assessment information.

Unit 1: an examination of what online learning is and "how will it affect me?"

Unit 2: a closer look at online learning covering interaction, communication systems and success factors.

Unit 3: ways of assisting online learning, using online resources, skills support and tutor support.

The communication systems used within this module are:

Mail: an internal e-mail system that allows participants to communicate with the facilitator and send completed work to them.

Discussion Forum: this allows participants to post public responses to unit activities Unit.

Chat: allows real-time discussion between participants.

Profile: participants create their own web page within the WebCT module.

Four cohorts have now completed the module. The participants have mostly been drawn from the help desk and learner support staff but other staff who have requested a place (for example, Issue Desk and Media Services staff) have been accommodated. A total of 44 staff have now undertaken the module and 30 portfolios have been submitted. As with ProVIDE, this module has been carefully evaluated and feedback has been obtained from WebCT usage statistics, the content of discussion postings, completed portfolios and evaluation forms. Feedback tells us that participants value the flexibility that e-learning offers. Content and design of the environment scores highly but participants struggle with their time management and motivation, commenting that it can be isolating learning online. Interestingly, during the pilot run of the module $66.7 \%$ of participants said they would choose to take another online course and $55.5 \%$ claimed they found it easy to learn online. ${ }^{8}$

\section{Customer care - an e-learning case study}

The enthusiastic response of Learning Services staff to their first experiences of online learning led us to develop a module in customer service skills, a 'soft skill' commonly delivered through instructor-led training. Customer Service is a popular skills area that over three quarters of organisations provide for their staff. ${ }^{9}$ Our decision not to buy an 'off the shelf' training product was based upon a number of factors. Firstly, our research into elearning that suggested that participants did not enjoy working with generic course materials, finding them to be irrelevant and lacking authenticity. ${ }^{10,11}$ Secondly, we were keen to deliver a module that was based on the sound educational principles and practice of social constructivism. This pedagogical view is, according to Mayes, ${ }^{11}$ based upon "collaborative learning, authentic tasks, reflection and dialogue”. The learning tasks must, therefore, be designed to be authentic to the work and social context in which the skills are normally employed.

In practice, this means that we do not see online learning comprising solely the digitisation of our printed customer care training materials, as this simply exposes our learners to inert facts and information. We want to offer them an experience that enables them to plan, act, reflect and discuss. To reinforce our view of the importance of the module, we consider it essential that participants demonstrate that they have met the learning outcomes with the production of a portfolio. By this means, we can ensure that the delivery methods are aligned with the learning outcomes, which state that by the end of the module participants will be able to:

- $\quad$ describe the theory and potential benefits behind customer care initiatives 
- $\quad$ identify who their customers are and what their needs and expectations might be

- $\quad$ apply customer care theory to their working practices

- $\quad$ apply Learning Services basic customer care guidelines

- $\quad$ identify their own customer care skills and develop an action plan for their further development

We also want the module to recognise that Learning Services staff have already acquired considerable skills and experience as both givers and receivers of customer care and to somehow incorporate this into the module's ongoing development.

The development process brought together the knowledge and experience of two information professionals (one of whom is the Lending Services manager), and a learning technologist. This range of expertise has ensured that the module has been developed with an understanding of the technological, pedagogical and customer care issues. The collaborative process the team undertook should also be viewed as a learning process in its own right and can be illustrated diagrammatically by applying Kolb's ${ }^{12}$ model of experiential learning (Fig 3). This iterative approach has proved to be particularly productive, resulting in an organic, constructivist approach where our focus has been upon the probable experience of the user. The team's problematising, 'real talk' approach, as defined by Jarvis, ${ }^{13}$ has resulted in their producing a range of interactions for the learner, with the content and other participants. The team has also introduced strategies to promote online learning, for example:

- $\quad$ all examples and resources used within the tutorial are linked to the learners' current workplace needs,

- $\quad$ an online entry- and exit-point skills audit has been written to identify where skills 'gaps' may occur and provide an opportunity to reflect upon how they have been resolved,

- $\quad$ use of visual, audio and animated examples to explain abstract concepts, where the learner interacts with the technology and to some extent, has control over what they are seeing,

- $\quad$ summative quizzes created in Hot Potatoes software and embedded within the pages of content,

- $\quad$ opportunities for learners to apply problem solving and research skills using 'real world' activities and to reflect upon the outcomes,

- a moderated discussion forum that provides opportunities for reflection, collaborative problem-solving and sharing of experience.

This reflective and iterative process (Fig 3) aimed to avoid the temptation to use technology for its own sake, rather to weave it seamlessly through the pedagogy and module content in a way that added value to the learning. It also sought to prevent what Iverson ${ }^{14}$ calls 'interaction overload' through the bombarding of learners with quizzes, discussion postings, animations and other types of interaction. She states "Achieving balance in interactivity is an important goal in e-learning design and activity”. 
Fig 3 The development process of the Customer Care module

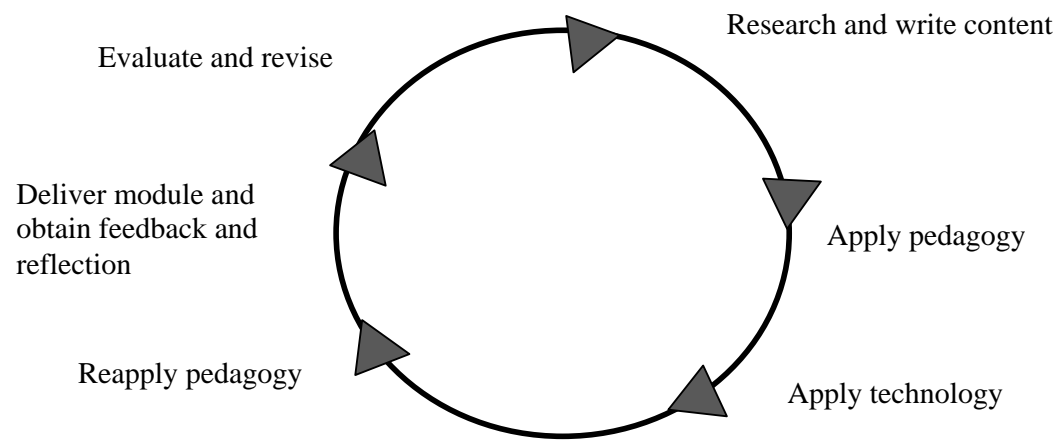

The Customer Care module comprises 6 units of content, a resources section and a Wiki (Fig 4). A Wiki is a web site that allows a user to add content, but also allows that content to be edited by anybody. The purpose of the Wiki in the context of this module is to enable learners to share their own experiences and knowledge of customer care with present and future participants on the module, with the hope of making it an organic, continually developing resource.

Fig 4 The Customer Care module home page

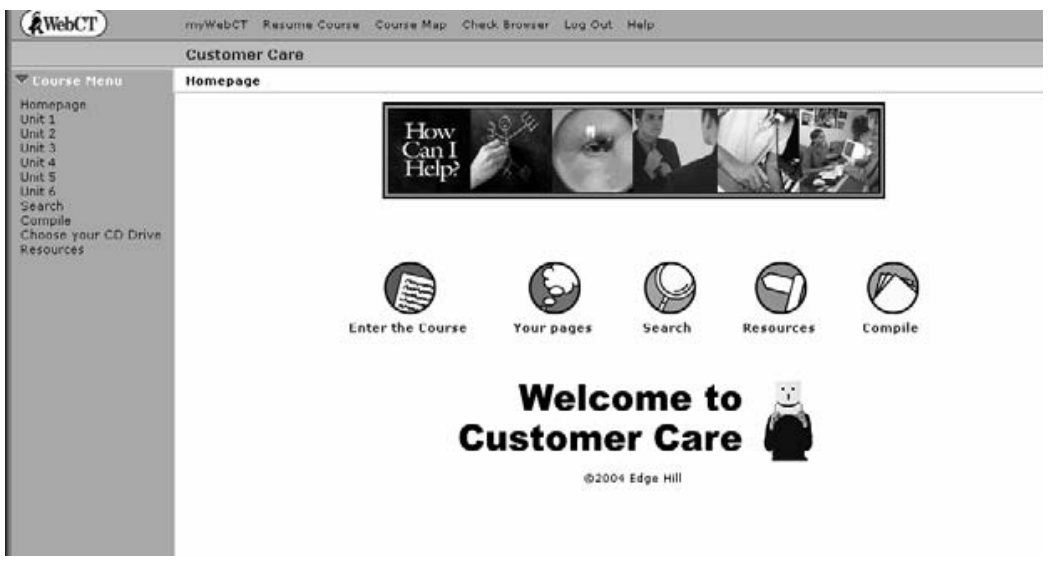

The module runs over four weeks and is introduced to the participants at a face-to-face session. It requires a time-commitment of between 2-4 hours a week and participants must produce a portfolio consisting of their contributions to the module tasks and their reflections on what they have learned. The six units (see fig 5) are:

Unit 1: Introducing Customer Care provides an orientation to the module and an opportunity to undertake a self-audit of existing customer care skills. The task at the 
end of this unit requires the participant to reflect upon their current customer care strengths and weaknesses and the nature of any skills 'gap'.

Unit 2: Customer Care theory looks at definitions of customer care and the theory behind how organisations keep or lose customers. This unit also contains an animation, a quick quiz and two video case studies.

Unit 3: Identifying our customers' takes a close look at who our customers are and why it is useful to break them down into segments and to analyse their specific needs.

Unit 4: Putting theory into practice looks at verbal and non-verbal communication skills, and the management of conflict. This unit contains a quiz and a video containing real-life tips for delivering excellent customer care.

Unit 5: Some Learning Services guidelines places the learning from the preceding units firmly in the context of Learning Services, its mission, policies and ethos. This is because we consider a thorough knowledge of the organisation one works is essential for the delivery of excellent customer care. This unit contains a series of staff development PowerPoint presentations to which an audio narrative has been added.

Unit 6: Putting it all together provides an opportunity for the learner to review their progress through the module and identify any remaining skills gaps around customer care. It also requires the learner to construct an action plan for their continuing development in customer care delivery.

Each unit follows a consistent design and structure to enable learners to find their way around the content. The pages within each unit include learning outcomes for each unit and a statement containing the number of pages and activities in each unit. Pages are broken up with coloured 'box outs' that contain relevant quotes or tips for the learner and links to interactive elements which are readily identified by a character called 'Colin Care' (Fig 6). Each unit also has a 'Take Notes' option where learners can capture their reflections online. These notes remain private, solely for the use of the individual learner and can be used to build their portfolio content. Finally, each unit concludes with a reflective task, which requires the leaner to use the 'Take Notes' facility. All tasks explain the purpose behind the task, for example:

Purpose: To reflect upon your understanding of who our customers are and to connect this understanding to the services that we provide.

Task: Now that you have completed this unit we would like you to spend some time thinking about our customers and how the services we provide meet their needs.

a) Does it help you to think in different groups or segments of customers?

b) Is it our business to tailor our services to customer groups or should we offer a service where customers fit in with routines that suit the service and its staff?

c) What, in your opinion, are the basic needs of customers using our services?

d) How useful do you find the various information-seeking strategies outlined on page 4 of this Unit?

Click on the Take Notes link on the action menu at the top of the WebCT tutorial page. You can use the Take Notes facility to record your thoughts.” 
Fig 5 The six units

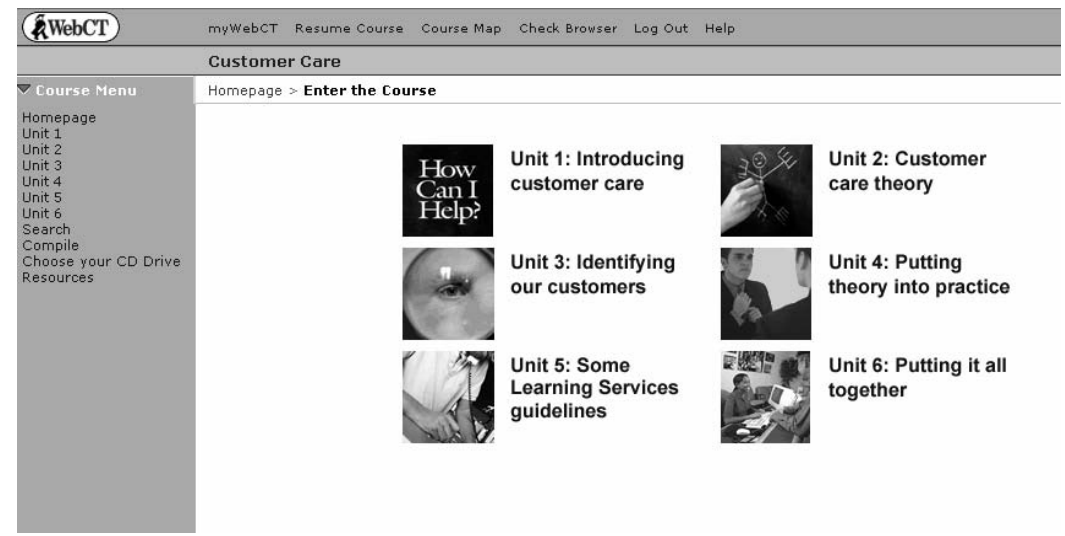

Fig 6 The layout of a page within a unit

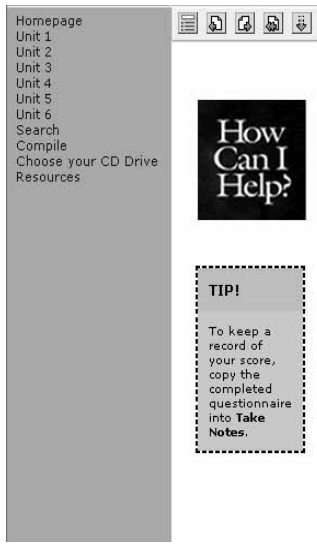

Take Notes

\section{Your first task for this section}

Before you make a start on the theory and practical application of customer care training, it is important that you take some time to think about your present level of skills and experience in this field. Have a go at completing the self-evaluation questionnaire below.

Evaluate your customer care skills

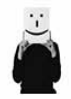

You will need to keep a record of how you scored in order to complete the portfolio reflection task on the next page. What are your first thoughts about the results of the self-evaluation questionnaire? Make a note of your thoughts in 'Take Notes'.

During the development of the module, the team sought the co-operation of the Learning Services staff through asking for their 'top tips' and requesting volunteers for video case studies. Staff volunteers also had access to the module while it was in development and were invited to give their constructive feedback. As the module neared completion and was ready for beta testing, all new Learning Services staff were also asked to work through the module as part of their induction programme. In all fifteen staff have now had access to the tutorial during the beta testing and their feedback has been very positive. The early indications are that we have achieved a good balance of interactivity. The quizzes and multimedia material have been particularly well received and participants state that they consider that these features have aided their learning. We have also been able to analyse the amount of use participants have made of the module through WebCT's tracking facility. The usage statistics also demonstrate a strong engagement with the module content. 
Our next step is to move beyond beta testing and run the module as part of the annual staff development programme in January 2005. A wide range of staff have applied to participate on the module and will submit completed portfolios, which will be assessed by the development team. The module will commence with a face-to-face session that will include an opportunity for hands-on with the module. It will also provide an opportunity for staff to meet and get to know one another through use of ice-breaking activities around customer care. Thereafter, the learning will be solely online and will be facilitated by the module development team. Two of that team are experienced at online facilitation and the third has experienced being an online learner through participating on the Supporting Online Learning module.

In line with our usual reflective/evaluative process of developing e-learning (and indeed, any other learning), we will carefully evaluate the module to ensure that the learners' experience was positive, that the interactivity was of an appropriate nature and amount, and that the assessed work demonstrates that the stated learning outcomes have been met. The evaluation will be drawn from completed participant feedback questionnaires, contributions to the discussion forum and Wiki, WebCT usage statistics and an analysis of the completed portfolios. This evaluation will be the subject of a further report in the summer of 2005 .

\section{Further training and development}

The e-learning examples described in this paper are not the only courses and resources made available to Learning Services staff. To enable the effective operation of multiprofessional teams, for example those staff working in learning support and learning technology roles, further training and development is available to complement project work as follows:

- $\quad$ an eight-week Developing and Delivering Online Learning course,

- $\quad$ additional, specialised workshops, for example, e-administration, emoderating, technical skills,

- $\quad$ information skills online to support staff on Help Desks.

We are also investigating how we can add value to the Supporting Online Learning and Customer Care modules through obtaining accreditation. Staff feedback clearly indicates that accreditation would be a welcome development and would have a demonstrable impact on the motivation of staff when learning online.

\section{Conclusion}

Edge Hill's Learning Services has adopted an innovative and strategic approach to its staff development needs in response to the e-learning imperative. By ensuring that all staff are equipped with the necessary baseline skills, the service has been able to respond to the swell of demand for learner support and requests for advice and collaboration in the use of eresources. Our bespoke approach to designing online modules for staff development has ensured that learners receive an experience that is rooted in their work and social context and offers an environment where they can plan, act, reflect and discuss. This contention is supported by our detailed evaluations of the WebCT modules that we have created. Our challenge is threefold: to continue with our multi-disciplinary, iterative team process of developing authentic e-learning opportunities; to add value to the learner's experience through obtaining accreditation for our online modules, and finally, through our ongoing staff development, to work towards 'e-everything!' where e-support and e-learning are regarded as commonplace and account for $50 \%$ or more of delivery. 


\section{References}

${ }^{1}$ Salmon, G. Pedagogical requirements of Virtual Learning Environments (VLE's): pets \& planets. The 24 hour University: Stretching the Limits: UCISA TLIG-SDG User Support Conference, Leeds UK April. 2002. URL

$<$ http://www.atimod.com/research/presentations/Salmonleeds.htm>

${ }^{2}$ Gilbert, S. W. A new vision worth working toward: connected vision and collaborative change, The TLT Group, URL <http://www.tltgroup.org/resources/vwwt.html>

${ }^{3}$ Rowley, J. JISC User Behaviour Monitoring and Evaluation Framework: Framework Report to 2002 (Cycles 1-3). [2 vols: FE and HE]. London: Joint Information Systems Committee, 2000.

${ }^{4}$ Russell, B. Analysing e-journal usage data for mutual benefit. Library and Information Update 2004, 3 (6), 36-37.

${ }^{5}$ Black, C. \& Roberts, S. Staff without walls: developing library and information staff for elearning. In: Brophy, P. Fisher, S. \& Craven, J. (eds) Libraries Without Walls: The Distributed Delivery of Library and Information Services. London: Facet, 2004.

${ }^{6}$ Oldroyd, M. (ed.) Staff Development in Academic Libraries: Present Practice and Future Challenges. London: Library Association Publishing, 1996.

${ }^{7}$ Salmon, G. E-moderating: The Key to Teaching and Learning Online. London: Routledge, 2000.

${ }^{8}$ Forsyth, A. Exploring New Learning Landscapes: Edge Hill's Supporting Online Learning Module. [Unpublished] Edge Hill College of Higher Education, 2002.

${ }^{9}$ Young, K. Is e-learning delivering ROI? Industrial and Commercial Training 2002, 34 (2), 54-61.

${ }^{10}$ Paton, N. Work: hard lessons from the big e-learning experiment: Nic Paton discovers why the much-hyped new way of workplace training has failed to deliver on its promises and why so many staff just don't want to know. The Guardian 2003. 30 August, Jobs \& Money: 5.

${ }^{11}$ Mayes, T. Learning technology and learning relationships. In: Stephenson, J. (ed.) Teaching and Learning Online: Pedagogies for New Technologies. London: Kogan Page. 2001.

${ }^{12}$ Kolb, D. A. Experiential Learning: Experience as the Source of Learning and Development. New Jersey: Prentice Hall, 1984.

${ }^{13}$ Jarvis, P., Holford, J. \& Griffin, C. The Theory and Practice of Learning. $2^{\text {nd }}$ ed. London: Kogan Page, 2003.

${ }^{14}$ Iverson, K. E-learning Games: Interactive Learning Strategies for Digital Delivery. New Jersey: Prentice Hall, 2004. 